13 Dagenais GR, Rouleau JR, Christen A, Fabia J. Survival of patients with a strongly positive exercise electrocardiogram. Circulation 1982;65:452-6.

14 Podrid PJ, Graboys TB, Lown B. Prognosis of medically treated patients with coronary-artery disease with profound ST-segment depression during exercise testing. $N$ Engl $f$ Med disease with pro $1981 ; 305: 1111-6$.

15 Burggraf GW, Parker JO. Prognosis in coronary artery disease: angiographic, hemodynamic, and clinical factors. Circulation 1975;51:146-56.

16 Hammermeister KE, DeRouen TA, Dodge HT. Variables predictive of survival in patients with coronary disease: selection by univariate and multivariate analyses from the clinical, electrocardiographic, exercise, arteriographic, and quantitative angiographic evaluations. Circulation 1979;59:421-30.

17 Bertolasi CA, Tronge JE, Riccitelii MA, Villamayor RM, Zuffardi E. Natural history of unstable angina with medical or surgical therapy. Chest 1976;70:596-605.

18 Rahimtoola SH. Coronary bypass surgery for unstable angina. Circulation 1984;69:842-8.

19 Russell RO, Moraski RE, Kouchoukos N, et al. Unstable angina pectoris: National Cooperative Study Group to compare surgical and medical therapy. Am $\mathcal{Y}$ Cardiol 1978;42:839-48.

20 Selden R, Neill WA, Ritzmann LW, Okies JE, Anderson RF. Medical versus surgical therapy for acute coronary insufficiency: a randomized study. N Engl f Med 1975;293:1329-33.
21 Pugh B, Platt MR, Mills LJ, et al. Unstable angina pectoris: a randomized study of patients treated medically and surgically. Am $\mathcal{F}$ Cardiol 1978;41:1291-7.

22 Gerstenblith G, Ouyang P, Aschuff S, et al. Nifedipine in unstable angina: a double-blind, randomized trial. N Engl $\}$ Med 1982;306:885-9.

23 Lewis HD Jr, David JW, Archibald GD, et al. Protective effects of aspirin against acute myocardial infarction and death in men with unstable angina: results of a Veterans Administration Cooperative Study. N Engl f Med 1983;309:396-403.

24 Mulcahy R, Daly L, Graham I, et al. Unstable angina: natural history and determinants of prognosis. Am f Cardiol 1983;48:525-8.

25 Mock MB, Ringqvist I, Fisher LD, et al. Survival of medically treated patients in the Coronary Artery Surgery Study (CASS) registry. Circulation 1982;66:562-8.

26 Ryan TJ, Bailey KR, McCabe CH, et al. The effects of digitalis on survival in high-risk patients with coronary artery disease: the Coronary Artery Surgery Study (CASS). Circulation $1983 ; 67: 735-42$.

27 Wallis WA, Roberts HV. Statistics: a new approach. Brooklyn: Free Press, 1956:467-8.

(Accepted 11 November 1986)

\title{
Psychiatric morbidity among spouses of patients with stroke
}

\author{
T C M CARNWATH, D A W JOHNSON
}

\begin{abstract}
The medium term psychiatric morbidity of spouses of patients with stroke was evaluated one to three years after the event. Compared with a control group the spouses were more likely to be depressed $(p<0.005)$ and had more physical symptoms $(p<0.01)$. Depression increased with the severity of the stroke in the spouse $(p<0.05)$ and with time during the three years. Regular contact with friends and neighbours protected spouses $(p<0.005)$. Depressed spouses were more likely to be taking tranquillisers than non-depressed spouses $(p<0.0001)$ but no more likely to be taking antidepressants. Social rehabilitation after stroke was less successful when the spouse was depressed.

Proper attention paid to spouses of patients with stroke might improve the prospects of these patients.
\end{abstract}

\section{Introduction}

Stroke is responsible for the disabilities of about $24 \%$ of severely handicapped people living in the community.' Stroke is also responsible for a large burden on those who care for these sufferers. ${ }^{2}$ Some carers find it difficult to cope, which may have a profound effect on the rehabilitation of patients with stroke. After the first year there is little or no further recovery of physical function, but there are large differences among patients in the level of social rehabilitation that they achieve. ${ }^{3}$ It has been shown how an overprotective attitude by spouses may adversely affect rehabilitation. ${ }^{4}$ Possibly depression in spouses may also hinder progress in patients with stroke.

This study aimed at discovering the prevalence of depression and other psychiatric illness in the spouses of patients with stroke and seeing how far it correlated with poor progress by the patient. A further aim was to delineate factors which might make spouses more vulnerable to mental illness and so suggest strategies of prevention.

\footnotetext{
Department of Psychiatry, University Hospital of South Manchester, West Didsbury, Manchester M20 8LR

T C M CARNWATH, MRCPSYCH, MRCGP, research fellow in psychiatry D A W JOHNSON, MD, FRCPSYCH, consultant psychiatrist
}

Correspondence to: $\mathrm{Dr} T$ C M Carnwath, Tone Vale Hospital, Norton Fitzwarren, Somerset TA4 1DB.
By comparing spouses with controls we also hoped to define the various disadvantages suffered by families of patients with stroke. In this paper we refer to spouses of patients with stroke simply as "spouses" and to patients with stroke as "patients."

\section{Subjects and methods}

We tried to identify all married people under 75 living in Stockport who had had a stroke between one and three years previously. Stockport is a largely urban area just outside Greater Manchester. Patients were identified from hospital records and by contact with general practitioners, district nurses, and the community physiotherapy service. In a prospective study in the same area all cases of stroke had been identified as they occurred through contact with general practitioners and hospitals. ${ }^{5}$ That study allowed an estimate of the number of cases that we were likely to find, and on this basis we think that over $95 \%$ of patients were eventually identified.

A total of 103 couples in whom both members were still alive were identified and interviewed at home. Two further couples refused interview.

A control group of 51 couples was selected from the age and sex registers of two group practices in Stockport. Neither member of these couples had had a stroke. Patients were selected at random from the practice lists and admitted to the study if they matched members of the index group for age, sex, and social class and were also married. None of the controls refused to be interviewed. There were no significant differences between the groups as regards past medical or psychiatric history or family history of mental illness. Interestingly, the control group had suffered more deaths of close relatives during the previous year $(\mathrm{p}<0.05)$.

\section{INTERVIEWS}

Spouses and controls were interviewed using the psychiatric assessment schedule, ${ }^{6}$ which is a slightly expanded version of the present state examination $^{7}$ and has been used successfully in a previous survey. ${ }^{6}$ The technique permits psychiatric diagnosis both by computerised processing of the present state examination (CATEGO) and also by research diagnostic criteria. ${ }^{8}$ When depression was diagnosed it was assessed by the Hamilton rating scale. ${ }^{9}$ Physical symptoms were scored using the PILL rating scale. ${ }^{10}$ Social problems were assessed by means of the social stress and support interview. " Various specific questions were asked about such things as personal and medical history, help from neighbours and local services, tablets taken, and so on.

The physical state of the patient was assessed by the Barthel index..$^{12}$ Clinical assessment was made of speech and memory difficulties. The Frenchay activity index was used to assess the extent of the patient's activities. ${ }^{13}$ Patients were asked to assess themselves on an eight point visual scale on the following items: depression, sexual disability, irritability, 
sleeplessness, and pain. Specific questions were asked about such matters as personal and medical history, history of the illness, use of services, and so on.

\section{STATISTICAL ANALYSIS}

Data were analysed using the statistical package for the social sciences on a mainframe computer at the University of Manchester. The $\chi^{2}$ test and the Mann-Whitney $U$ test were used as appropriate. A $5 \%$ level of probability was taken as significant. Discriminant function analysis was also performed.

\section{Results}

\section{COMPARISON OF STROKE GROUPS WITH CONTROLS}

No mental illness was identified in the series apart from depressive illness. Forty spouses in the stroke group (39\%) were found to be depressed by research diagnostic criteria. Eight were categorised as definite minor depression, 15 as probable major depression, and 17 as definite major depression. In the control group six spouses (12\%) were depressed (three definite major, three definite minor depression). This difference was highly significant $(p<0.005)$. Of those diagnosed as depressed in the stroke group 31 . $(78 \%)$ had Hamilton scores of 18 or more, indicating moderate or severe depressive illness.

Thirty six members of the stroke group (35\%) and four of the controls (8\%) were diagnosed as having depressive illness by CATEGO processing of the present state examination results. The difference between groups was highly significant $(\mathrm{p}<0.005)$.

Discriminant function analysis was performed on controls and subjects grouped together with depression as the dependent variable. The following factors in the spouses, found to be independent predictors of depression, are listed with the standardised canonical discrimination function coefficients: coincident physical illness $(0.53)$; marital stress $(0.46)$; occupational stress $(0.45)$; marriage to patient with stroke $(0.36)$; stress relating to housing $(0 \cdot 19)$. On this basis $82.91 \%$ of cases could be correctly classified. This supports the hypothesis that stroke plays a part in producing depression in the spouse of the patient.

Subjects in the stroke group were significantly more disadvantaged than the controls (table I).Spouses were more likely to be dissatisfied with their occupation, their social life, and their housing when assessed by the social stress and support interview. The patients suffered more from depression, irritability, pain, insomnia, and sexual problems.

Using research diagnostic criteria we tried to discover the proportion of

TABLE I-Difficulties more frequent in stroke group than controls

\begin{tabular}{lllc}
\hline Complaint & $\mathrm{pV}$ Value & Complaint & $\mathrm{pValue}$ \\
\hline Spouse depressed & $<0.005$ & Patient irritable & $<0.0001$ \\
Spouse unhappy with occupation & $<0.005$ & Patient with sleep difficulties & $<0.01$ \\
Spouse unhappy with social life & $<0.01$ & Patient with sexual problems & $<0.0001$ \\
Housing problems & $<0.001$ & Patient in pain & $<0.01$ \\
Patient depressed & $<0.0001$ & &
\end{tabular}

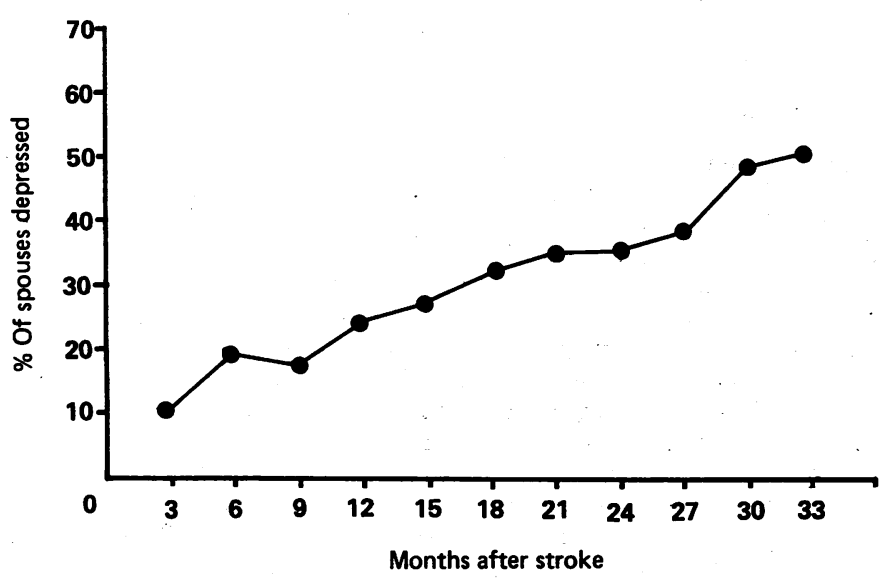

Proportions of spouses depressed at various times after patients' strokes. spouses in the stroke group who had been depressed at particular intervals after the patients' strokes. The figure shows that the proportion increased with time $(p<0.005)$. Whereas the level of patients' physical disability decreased significantly with time during the study $(\mathrm{p}<0.05)$, marital stress increased $(p<0.05)$, as did the amount of medication taken by spouses $(\mathrm{p}<0.01)$.

\section{COMPARISON OF DEPRESSED WITH NON-DEPRESSED SPOUSES IN STROKE GROUP}

Couples with a depressed spouse at the time of interview were compared with other couples in the stroke group using research diagnostic criteria (table II). Depressed spouses were more likely to have physical illnesses themselves as assessed by the PILL scale. They were also much less likely to have frequent contact with their neighbours. The patients in these couples were rated on the Barthel scale as being more physically dependent in various ways. They were also more likely to be suffering from depression, pain, irritability, and sleep disturbances. Their participation in social activities and interests outside the home as rated by the activity scale had decreased to a greater extent. Interestingly, though depressed spouses were taking more sedatives and more non-psychotropic drugs, they were not more likely to be taking antidepressants.

TABLE II-Difficulties more frequent in depressed than non-depressed couples affected by stroke

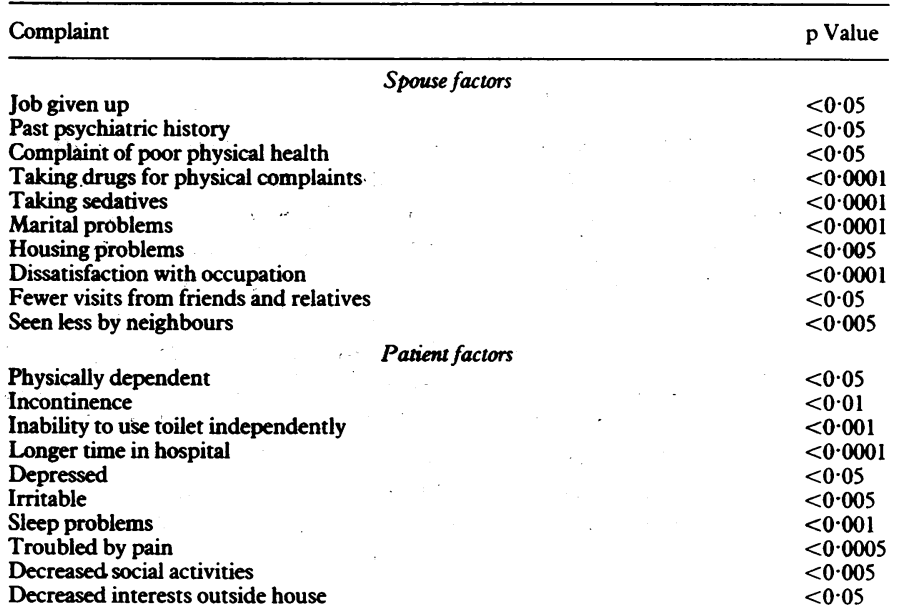

\section{Discussion}

Brocklehurst et al confirmed that the spouses of patients with stroke are likely to get depressed. ${ }^{5}$ Nevertheless, that depression is likely to be present a considerable time after the stroke has not been reported, and our findings show that it is more common three years after the stroke than after the first year. We should be interested to know whether this is still true five and 10 years after the initial illness: The high prevalence of depression in our series is all the more striking given that the study dealt with all types of strokes, including those leaving minimal disability.

Spouses often give up jobs and interests to look after their partners with stroke. Often they have social and financial problems and they may get isolated from friends and relations. On top of this, the relationship with their affected partner often changes radically. Sometimes the patient is aphasic and communication becomes very difficult. More frequently spouses complain that the personality of the patient has changed since the stroke. Patients who reported high levels of irritability and depression were more likely to have depressed spouses $(p<0.005)$. Even in patients whose strokes seemed to have left little disability spouses frequently complained of personality changes.

Unemployed women who have young children to look after and do not enjoy a confiding relationship with husband or lover are very vulnerable to depression. ${ }^{14}$ People caring for patients with stroke 
seem to be in a similar situation. In both cases there is a constriction in the repertoire of roles they perform in life. The only role or activity left for spouses of patients with stroke may be caring for their partner, which often gives little satisfaction. In time resentment and guilt about this resentment frequently develop. Overprotection of the patient may be the result of compensation for the guilt. This often leads to irritability and resentment in the patient, who is already feeling guilty and depressed himself. Quite commonly relationships between couples were noted to be extremely tense. This was exacerbated when for most of the week couples saw nobody else but each other.

After the first year little physical improvement can be expected in patients with stroke. ${ }^{5}$ The difference between successful and unsuccessful rehabilitation at this stage depends on the degree to which social interests, activities, and occupations are taken up again. ${ }^{3}$ This study shows that depression in the spouse may be an important factor militating against such rehabilitation. If the spouse does not feel like seeing anybody it is very hard for the patient to take the initiative and organise it himself. It seems likely that helping spouses overcome their own depression may play an important part in the rehabilitation of patients at this stage.

We were surprised that so few of the depressed spouses had been prescribed antidepressants even though they had symptoms which suggested that they might respond. General practitioners seemed reluctant to prescribe antidepressants when the depression was thought to be a reaction to adverse personal circumstances. Most depressed spouses were taking minor tranquillisers instead. None the less, when it was suggested to general practitioners that antidepressants should be prescribed for particular patients they frequently responded well: Benzodiazepines are often used in primary care for the treatment of depression despite the lack of evidence that they are effective. ${ }^{\text {is }}$

Most spouses felt neglected and that little had been done for them after the first six months. Though there are active stroke clubs in the area, spouses felt that the clubs helped patients but not themselves. A branch of the Association of Carers was started in Stockport at the end of the study and received widespread support from spouses. Most spouses resented the idea that they needed psychological help. None the less, most believed that they could have been told more and given more support. This study suggests that contact with friends and neighbours is particularly important.

Research is needed to discover how far support and information meetings might be able to prevent depression in spouses of patients with stroke. Though this type of group has been set up in some areas, ${ }^{16}$ this study suggests that groups may need to continue for longer than usually happens. Probably a more refined psychological input to such meetings could be evolved. A clear priority is to discover whether the rehabilitation prospects of patients with stroke can be measurably improved by reducing the prevalence of depression in their spouses.

We thank Professor D P Goldberg, Dr C Dean, and Dr J Leeming for their helpful advice and Dr V Hillier for help in analysing the data. We thank Lundbeck Ltd for sponsoring the research fellowship to TC.

\section{References}

1 Harris $\mathrm{AI}, \mathrm{Cos}$ E, Smith CHW. Handicapped and impaired in Great Britain. P1. London: Office of Population Censuses and Surveys, HMSO, 1971.

2 Carstairs V. Stroke; resource consumption and cost to the community. In: Gillingham FJ, Mawdesley C, Williams AE, eds. Stroke. London: Churchill Livingstone, 1976.

3. Gresham GE, Phillips TF, Wolf PA, McNamara.PM, Kannel WB, Dawber TR. Epidemiologic profile of long-term stroke disability: the Framingham study. Arch Phys Med Rehabil profile of long-
$1979 ; 60: 487-91$.

4 Andrews K, Stewart J. Stroke recovery; he can but does he? Rheumatol Rehabil 1978;18:43-8.

5 Brocklehurst JC, Andrews K, Morris PE, Richards B', Laycock PJ. Why admit stroke patients to hospital? Age Ageing 1978;7:100-8.

6 Dean C, Surtees PG, Sashidharan SP. Comparison of research diagnostic symptoms in an Edinburgh community sample. Br $\mathcal{F}$ Psychiatry 1983;142:247-57.

7 Wing JK. The measurement and classification of psychiatric symptoms. Oxford: Oxford University Press, 1974.

8 Spitzer RL, Endicott J, Robins E. Research diagnostic criteria: rationale and reliability. Arch Gen Psychiatry 1978;35:773-82.

9 Hamilton M. Development of a rating scale for primary depressive illness. British fournal of Social and Clinical Psychology 1967;6:278-96.

10 Pennebaker JW. The psychology of physical symptoms. New York: Springer-Verlag, 1982.

11 Jenkins R, Mann AH, Belsey E. The social stress and support interview. Soc Sci Med 1981;15E: 195-203.

12 Mahoney FI, Barthel DW. Functional evaluation-the Barthel index. Md State Med $\mathrm{J}$ 1965;14:61-5.

13 Holbrook M, Skilbeck CE. An activities index for use with stroke patients. Age Ageing 1983;12:166-70.

14 Brown GW, Harris T. The social origins of depression. London: Tavistock Free Press, 1978.

15 Johnson DAW. The use of benzodiazepines in depression. Br $\mathcal{J}$ Clin Pharmacol 1985;19:318-58

16. Holbrook M. Stroke: social and emotional outcome. I R Coll Physicians Lond 1982;16:100-4.

(Accepted 3 December 1986)

\section{Renal failure and the histopathological features of myeloma kidney reversed by intensive chemotherapy and peritoneal dialysis}

Impaired renal function is seen in over a half of patients with multiple myeloma, and, though hypercalcaemia, urinary infections, and hyperuricaemia are sometimes contributory, oliguric renal failure due to myeloma kidney is usually ascribed to the toxic effects of urinary immunoglobulin light chains. ${ }^{1}$ Rehydration may improve renal function in some cases ${ }^{2}$ but the remainder require continuous haemodialysis. Since peritoneal dialysis may be more effective at removing circulating light chains, however, ${ }^{3}$ we have used this in combination with a new chemotherapeutic regimen ${ }^{4}$ in an attempt to reverse the morphological abnormalities of myeloma kidney in a patient with oliguric renal failure.

\section{Case history}

A 54 year old woman presented with a fractured metacarpal and was treated with indomethacin. She became tired and anorectic and was found to be uraemic and oliguric with a blood urea concentration of $39 \cdot 2 \mathrm{mmol} / 1(236 \mathrm{mg} / 100 \mathrm{ml})$ and a serum creatinine concentration of $2020 \mu \mathrm{mol} / 1(22.9 \mathrm{mg} / 100 \mathrm{ml})$. Drug induced interstitial nephritis was considered but renal biopsy showed typical features of myeloma kidney (figure).

Investigations showed a haemoglobin concentration of $100 \mathrm{~g} / 1$, a white cell count of $11.2 \times 10^{9} / 1$, and a platelet count of $153 \times 10^{9} / 1$. Serum immunoglobulin concentrations were: $\operatorname{IgG} 41.9 \mathrm{~g} / \mathrm{l}$ (normal 8-18 g/l), IgA 0.3 g/l (normal 0.9-4.5 $\mathrm{g} / \mathrm{l}$ ), and IgM $0 \cdot 4 \mathrm{~g} / 1$ (normal $0 \cdot 6-3 \cdot 0 \mathrm{~g} / \mathrm{l}$ ). There was an IgG paraprotein value of $32 \cdot 6 \mathrm{U} / 1$ and the urine free light chain concentration was $15 \cdot 1 \mathrm{U} / \mathrm{g}$ creatinine. The bone marrow contained $41 \%$ plasma cells and a skeletal survey showed generalised osteoporosis.

She had severe fluid overload and required urgent haemodialysis. When myeloma kidney was confirmed by renal biopsy, however, continuous ambulatory peritoneal dialysis was instituted to increase the clearance of immunoglobulin light chains. In addition, she received a four day continuous infusion of vincristine $0.4 \mathrm{mg} /$ day and doxorubicin $9 \mathrm{mg} / \mathrm{m}^{2}$ body surface area/day with dexamethasone $40 \mathrm{mg} /$ day for four days beginning on days 1,9 , and 17 of each three week cycle (VAD). After four courses the serum creatinine concentration had fallen to $456 \mu \mathrm{mol} / 1(5.2 \mathrm{mg} / 100 \mathrm{ml})$ and the blood urea to $27.9 \mathrm{mmol} / \mathrm{l}(168$ $\mathrm{mg} / 100 \mathrm{ml}$ ). Dialysis and VAD were then withdrawn and she was treated with intermittent courses of melphalan and prednisolone. Her renal function continued to improve, and at 12 morths the serum creatinine concentration was $258 \mu \mathrm{mol} / \mathrm{I}$ $(2.9 \mathrm{mg} / 100 \mathrm{ml})$. In addition, there were progressive reductions in the serum paraprotein concentration and urinary light chain excretion to $12.5 \mathrm{U} / 1$ and $2 \cdot 6 \mathrm{U} / \mathrm{g}$ creatinine, respectively. She resumed work as a physical education teacher and 15 months after diagnosis was leading a normal life. A second renal biopsy at eight months showed considerable improvement in the histological appearances (figure).

\section{Comment}

The regimen of VAD and continuous ambulatory peritoneal dialysis was well tolerated by our patient and there was no diarrhoea, vomiting, or hair loss. Urinary light chain excretion decreased rapidly, which was probably an important factor in her recovery. In view of previous reports additional plasmapheresis might also have helped in rapidly reducing serum light chains during this initial management. ${ }^{3}$

This is the first example in which the morphological abnormalities of 